DOI: 10.21892/978-958-5547-65-0.11

\title{
11. Del despojo al acaparamiento de tierras: los conflictos socio-ambientales emergentes en los Montes de María alrededor de la expansión de la palma africana y la teca
}

Mauricio Luna-Galván ${ }^{6}$

\section{Introducción}

Las dinámicas territoriales de los Montes de María, subregión entre los departamentos de Sucre y Bolívar, han sido de tipo conflictivas en su historia reciente, y el acceso a tierras y al agua para campesinos y comunidades, constituyen el centro de disputas. Lo anterior, partiendo de que "la alta informalidad de la tierra por parte de los campesinos y, por ende, la inexistencia de titulación o pruebas registrales de dominio sobre la mayoría de los predios, han hecho que la ruta de protección jurídica sea una figura inaplicable o poco útil en esta región del país, lo que igualmente ha facilitado la apropiación por parte de los despojadores" (Vargas, 2012).

Los municipios de María La Baja y Ovejas ofrecen casos ilustrativos del despojo en el marco del conflicto y la posterior pacificación bajo dinámicas de acaparamiento. Desde 1996, bajo la figura de las alianzas productivas, el distrito de riego fue entregado en concesión a Usomarialabaja, empresa que hasta la fecha lo sigue administrando. Desde entonces, se ha dado paso a cultivos de palma cuyo "distrito de riego cubre 19.600 hectáreas de tierras cultivables en María La Baja, Arjona y Mahates. En María La Baja hay 11.200 hectáreas sembradas con palma de aceite. Por su parte, los cultivos de Teca, se encuentran en San Onofre con 2400 hectáreas; Ovejas/Carmen de Bolívar, 1500 hectáreas de teca" (El campo tiene sed, 2016).

En Colombia aún transcurren trayectorias de luchas más conflictivas centradas en la tierra, "en el caso de los agricultores pequeños, hay

6 Internacionalista de la Universidad de Bogotá Jorge Tadeo Lozano. Máster en Estudios Globales de la Universidad de Lund, Suecia. 
vulnerabilidad en la tenencia de tierra que se deriva del conflicto armado y la falta de títulos de propiedad. En estas condiciones, hay pocas posibilidades para acceso de tierra a través del mercado, lo que obstaculiza su movilidad como factor de producción" (Informe Banco Mundial, 2006-2010).

El caso de los cultivos para agrocombustibles, las alianzas productivas llevan a cabo contratos de arrendamiento de tierra según el ciclo de vida del monocultivo y tienen una duración de 20 a 25 años, lo cual permite el control de las empresas sobre las tierras. Estas alianzas han conducido a la formalización de la propiedad de la tierra en los Montes de María, la cual se fundamenta por falsa tradición o ausencia de escrituras. La aprobación de la ley de titulación (Ley 182 de 2008) ha funcionado en pro de los grandes empresarios. Como resultado se observa que "las alianzas productivas sólo sirvieron para que el campesino legalizara su tierra para venderla a precio muy bajo" (Ojeda et al. 2015: 112-113).

Lo anterior, choca con el desarrollo rural en Montes de María está basado en la economía campesina, caracterizada fundamentalmente por una producción agropecuaria familiar, con pequeñas unidades de tierra, uso intensivo de la mano de obra familiar, alto nivel de autoconsumo de la producción y diversificación de actividades generadoras de ingreso al interior del hogar.

Hay que comprender los cambios en la industria agroalimentaria donde el comercio global desregulado, la financialización, y los avances en biotecnología y los métodos de producción están reorganizando rápidamente el sector (Margulis \& Porter, 2013: 71)

Es así como las transacciones de tierra y las políticas de intervención bajo el desarrollo como paradigma, está articulado a determinados contextos, como la narrativa política en el que los habitantes rurales, áreas y fronteras definidas como atrasadas. Dicha narrativa del desarrollo es transversal y repetida en los medios de comunicación, las áreas rurales, y las comunidades indígenas, mostradas frecuentemente como en la necesidad de cambiar su mentalidad colectiva con el fin de ser parte del desarrollo (Postil, 2006 en Oberborbeck).

Consecuentemente, el discurso subvalora la tierra en términos económicos, al mismo tiempo en la tenencia y el uso en manos de comunidades, eso termina generando constricciones legales en el uso de la 
tierra entre los terratenientes, habitantes rurales y los que usan los recursos de esos territorios que por tradición han vivido.

Es relevante como Oberborbeck encuentra la conexión de poderosas narrativas como el "desarrollo de las tierras sin utilizar" lo cual traerá a las personas a la ola del desarrollo, a través de la asociación del discurso de las relaciones con comunidades locales con los intereses y discursos políticos nacionales y las exigencias económicas transnacionales. Para el análisis, es clave ver cómo esos procesos políticos y económicos se intersectan con el desarrollo de la palma africana y de las semillas en los espacios. De lo anterior, el acaparamiento de tierras como fenómeno, profundiza y genera impactos bajo esa lógica de la política económica del capital global que profundiza las desigualdades y engendra conflicto social y ambiental.

Phillip McMichael (2013), asegura que se está presentando una "reterritorialización con el acaparamiento de tierras diseñado para evitar la dependencia en los intermediarios del mercado". El tipo de integración horizontal y vertical que las corporaciones promueven y buscan en la agricultura y las tierras cultivables por los Estados y como instrumento del capital financiero.

\section{El factor institucional en el conflicto de la expansión de la palma africana y la Teca}

En primer lugar, es clave comprender dicho proceso de "reterritorialización" a través de la toma de decisión a nivel institucional. Desde el nivel internacional la agenda gira en torno al aumento en la demanda global de alimentos para "satisfacer" las necesidades de humanos y no humanos, y para la producción energética; así mismo, la influencia que puede llegar a tener la Organización Mundial del Comercio (OMC) cuando se trata de abogar por los intereses de grandes empresas. En esa medida, un tercer régimen emerge como lo denomina McMichael (2009), el cual hace referencia al creciente poder de las corporaciones transnacionales tienden a gobernar el régimen en un contexto neoliberal y los Estados dan paso a las reglas comerciales y de precios establecidas por la Organización Mundial del Comercio (OMC), dejando expuestos a sus mercados doméstico agrícola al poder e influencias de las transnacionales agrícolas o a los grandes agronegocios. La globalización se presenta como el contexto que sienta las bases para un tercer régimen alimentario en el mundo, el 
cual está intrínsecamente relacionado con las políticas neoliberales que se profundizan a finales de los ochenta, convirtiéndolo así un régimen corporativo alimentario.

En el segundo nivel es el (ii.) nacional, y es aquí donde cobran forma a través de leyes y decretos, las decisiones anteriores y la implementación de Tratados de Libre Comercio. En este nivel no solo existen conflictos de interés político y económico entre los sectores primarios, sino también se le puede ver como un atomizador de conflictos sociales en los territorios locales. Finalmente, el tercer nivel es el (iii.) local, que para estos efectos se entiende como aquellos individuos/grupos productores que se ven afectados por las decisiones asociadas alteración de los procesos ecológicos naturales de la producción de alimentos, perdiendo así el poder de decisión en cómo y qué se cultiva. Tal situación ha generado la creación de diversos movimientos sociales que claman por justicia social y ambiental.

La expansión de la palma africana es impulsada por las predicciones de que para el 2030 el consumo de agrocombustible alcanzará los 250 billones de litros de gasolina equivalente por año, principalmente en el mercado de los biocombustibles en la Unión Europea (Borras, 166), así como otros productos de tipo industrial del cual se derivan.

Un efecto es el debilitamiento en el apoyo a los productores rurales bajo los mecanismos de asistencia social hacia otros por canales de responsabilidad empresarial de la agroindustria. La idea de desarrollo rural empieza a ser concebida como un proceso económico más y por lo tanto, "debe quedar en manos de un gerenciamiento empresarial" (sic.) (Gudynas, 2008, p. 169); profundizando de esta forma, la pobreza rural.

En consecuencia, fue notorio cómo las instituciones permitieron "cambios en la legislación en materia de propiedad de la tierra y quienes, con el respaldo de instituciones financieras internacionales como el Banco Mundial (BM), presionan a los gobiernos para que efectúen dichos cambios" (Álvarez Roa: Semillas).

La dinámica resultante de las transferencias negociadas de los derechos de propiedad legalizadas entre el gobierno con los propietarios tradicionales a los inversionistas es el acaparamiento de tierras contemporáneo, ya que "los Estados en los que se realizan las transacciones en tierras, protegen esas inversiones, esto a pesar de que muchas de las transacciones permanecen 
profundamente conflictivas, que la violencia esporádica continúa y que el acaparamiento de tierras ha incrementado la inseguridad de muchas comunidades" (Magulis \& Porter, 2013: 70-71).

En ese sentido, el superintendente de notariado y registro, Jorge Enrique Vélez, a marzo de 2012 ha identificado la compra masiva de tierras de más de 37.273 hectáreas en los Montes de María, de igual forma hectáreas tituladas de forma fraudulenta, 34 mil se encuentran en los Montes de María. Generando así, una escasez de tierra para la restitución y para el ejercicio del derecho a la tierra por parte de los habitantes históricos es evidente en el hecho de que de las 134.000 hectáreas entregadas por el Incora entre 1963 y 2007, 63\% (84.4230) están en manos de empresas y fiducias (Ramírez \& Tobón, 2012)

Dentro de estas empresas encontramos a Oleoflores, dedicada a la producción de aceite de palma para la industria alimenticia y biodiesel logrando controlar la mayor cantidad de tierra cultivada de tierra en Colombia, cerca de 25.000 hectáreas para 2011 (Ojeda, 112 de MartinBurgos). En el caso de la palma africana, nacen con el ex-ministro Carlos Murgas para el desarrollo rural de estas comunidades como estrategia para impulsar las "locomotoras del crecimiento" propuestas por el Plan Nacional de Desarrollo 2010-2014 del gobierno Santos. La figura de las alianzas productivas vincula a los campesinos locales en calidad de productores, y a los conglomerados empresariales como socios estratégicos. Los campesinos productores se comprometen a sembrar más de diez hectáreas en palma o son subcontratados como trabajadores de los cultivos. La empresa compradora del fruto es la que fija el precio de compra, muchas veces por debajo de los costos de producción (Ojeda, 2015: 112).

En cuanto al caso del cultivo de Teca es clave, porque son establecidos como depósitos de carbono y proyectos de reforestación en el Marco del Mecanismo de Desarrollo limpio por parte de la compañía colombiana Argos, las ventas sucesivas y su sucesiva especulación se dieron a través de vínculos con grupos paramilitares (Ojeda, 212, de Bargent, 2011: 88). 


\section{Factores conducentes al conflicto}

La subregión de los Montes de María se convierte en un laboratorio de paz tras un período de violencia, dando paso a llegada de grandes de inversión impulsadas por el gobierno, el cual le atribuye a la agroindustria un papel estratégico en la implementación y el éxito de las políticas de restitución y reparación (Ojeda, 111 de DNP 2010, 154). La empresarización de la actividad agrícola se empieza a consolidar en la región, y en esa medida reduciendo el acceso a la tierra y al agua de los locales.

El paisaje de los Montes de María, es agrodiverso, combina fincas campesinas con bosques secos tropicales, uno de los bosques más amenazados por la agroindustria y la ganadería a gran escala. La palma y los árboles de teca vulneran la estructura y la funcionalidad de los ecosistemas manejados por los campesinos, indígenas y afrodescendientes de la región. Sin duda, estos cultivos no solo controlan y concentran la propiedad y el uso de la tierra, sino que configuran un paisaje distinto donde el acceso al agua es limitado y controlado por las demandas de uno o dos cultivos controlados por la agroindustria. El agua entendida como recurso natural y derecho fundamental (Foro regional campesino, 11 de agosto de 2012).

Además, se encuentran con un antecedente complejo, "entre 1997 y 2010 el 55\% de la población fue expulsada, es decir que de los 430.000 habitantes de los quince municipios, 234.098 fueron obligados a desplazarse hacia los cascos urbanos principalmente. Pocas familias han retornado, por falta de garantías o porque desde su desplazamiento han pasado muchos años y al regreso tendrían que empezar de nuevo desde cero" (Ramírez y Tobón, 2012: 3). Durante el año 2000, la violencia armada generó el desplazamiento masivo de comunidades campesinas en Ovejas, 4 años después los habitantes se Villa Colombia y veredas aledaña decidieron retornar, sin imaginar que se enfrentarían a un problema mayor" (Documental).

Corporaciones Autónomas Regionales y de Desarrollo Sostenible encontramos a Cardique, la cual toma muestras para análisis físico químico del agua de la represa (20 noviembre, 2015). Para el mes de abril de 2016 los resultados no habían sido entregados a las comunidades. 
La Defensora del pueblo Regional Bolívar, Irina Junieles, ha insistido en incoder para tener planos de represa para determinar zonas de amoriguamiento.

Organizaciones campesinas: la creación, en 1967, de la Asociación Nacional de Usuarios Campesinos (ANUC), cuyo fin era apoyar al Instituto Colombiano de Reforma Agraria (Incora), creado para llevar justicia y calma a los campos colombianos que fueron arrasados por la violencia desatada en el país en los años cuarenta.

La trayectoria agrícola en los Montes de María da lugar a movimientos sociales campesinos que surgen en la segunda mitad del siglo XX, organizadas alrededor de sindicatos de trabajadores de las plantaciones, cooperativas y organizaciones veredales entre ellos la Asociación Nacional de Usuarios campesinos (ANUC), configurándose como un espacio de lucha campesina, cuyo objetivo fue procurar el acceso a la propiedad para los pobladores rurales, quienes hasta ese momento trabajaban la tierra a través de contratos de arriendo, pago en especie o acuerdos laborales con grandes propietarios" (Entrevistas de Ojeda, 2015).

En cuanto a los gremios empresariales, tenemos al empresario Carlos Murgas, llamado el "zar de la palma", dueño de uno de los grupos empresariales más grandes en Colombia, Oleoflores, se dedica a la producción de aceite de palma para la industria alimenticia y biodiesel logrando controlar la mayor cantidad de tierra cultivada de tierra en Colombia, cerca de 25.000 hectáreas para 2011 (Ojeda, 112 de MartinBurgos.) Es así un actor central en la expansión de los commodities agroindustriales extractivos. Dicha expansión se inicia en los Montes de María con la compra de 100 hectáreas en el antiguo molino de arroz del municipio de María La Baja bajo el modelo de las alianzas productivas. (Ojeda, 2015: 112). 


\section{Los cultivos de Palma de Aceite y la Teca en los Montes de María: un conflicto hacia lo sub-regional}

La problemática ambiental se dimensiona basada en su alcance geográfico de tipo local, sin embargo, el municipio de María La Baja, contiene recursos hídricos que representan el más alto potencial de la zona norte y centro del departamento de Bolívar, por la escorrentía que se genera en el municipio, los embalses de Matuya y Playón y el Pondaje el Viento, las aguas subterráneas, las áreas pantanosas y cenagosas asociadas al complejo cenagosos del Canal del Dique (Informe gestión de riesgos).

La represa de Arroyo Grande se construyó sobre el poblado de Palo Alto Hicotea, en la parte del distrito de riego del municipio de Marialabaja, construido en los años 60 para potenciar la producción de arroz de riego, uno de los cultivos que por más de 30 años dinamizó la economía campesina de la región". Para 1963, se inicia el proyecto en áreas que antes estaban cultivadas de plátano; maíz, ñame y arroz, y el gobierno compraba tierras (Documental).

"El arroyo Grande, con un caudal de $123 \mathrm{mts} / \mathrm{seg}$, y el arroyo de Matuya con caudal de $80 \mathrm{mts} / \mathrm{seg}$, son los más importantes en el área del municipio, por los servicios que prestan; arroyo Corral que baña los municipios de María La Baja al este de San Juan de Nepomuceno, entre sus afluentes están los arroyos de Quiebra Anzuelos y Mampujan localizados al este de la cabecera municipal, desemboca en la Ciénaga de María La Baja" (Informe gestión de riesgos ).

Embalse Matuya, está localizado en la parte sur oriental de la cabecera municipal una distancia de $11 \mathrm{~km}$. Más exactamente en el corregimiento de Matuya, vía calle 20 carrera 15 ruta la curva con la variante de la troncal de occidente, desviándose por la vía 40 barrio la suprema con un espejo que baña la vereda de la suprema y casa aisladas. Es alimentado por el arroyo de Matuya y las escorrentías que vienen de las serranías de los Montes de María.

El embalse de San José de Playón, está localizado en la parte suroriental de la cabecera municipal a una distancia de $20 \mathrm{Km}$., más exactamente en el corregimiento de San José del Playón, vía desde la variable la Troncal de 
occidente, desviándose por Nueva Esperanza, margen izquierda pasando por los caseríos Nuevo Reten, Arroyo Grande y el Guamo.

Con 2000 has el espejo de agua, que baña el mismo corregimiento y la vereda de Palo Altico, es alimentado por el arroyo Grande y las escorrentías que vienen de las serranías de los Montes de María. Los moradores de Matuya y María La Baja se abastecen de agua de la represa arroyo Grande del corregimiento de San José del Playón. Pero, el agua en esta zona es crucial porque no es potable a pesar de la gran fuente hídrica. Es de anotar, que el Incora en el pasado entregó tierras de acceso común en esta zona; pero, el agua y arroyos no se pueden privatizar, "y las empresas privadas del monocultivo de palma aceitera secaron sus pozos, y contaminaron sus fuentes de abastecimiento" (Revista Semana, junio 6 de 2017). En esta región, prácticamente ya no hay agua y la distancia es larga para acceder a ella; por lo que Playón y Palo Altico, carecen del acceso al agua a pesar de estar cerca de la represa.

Colombia aún existen luchas más conflictivas centradas en la tierra, "en el caso de los agricultores pequeños, hay vulnerabilidad en la tenencia de tierra que se deriva del conflicto armado y la falta de títulos de propiedad. En estas condiciones, hay pocas posibilidades para acceso de tierra a través del mercado, lo que obstaculiza su movilidad como factor de producción" (Banco Mundial Colombia 2006-2010). Los Montes de María representan un caso ilustrativo que se enmarca en un contexto de violencia política donde se llevaron a cabo masacres de forma sistemática. La formación de espacios de despojo constituye la prueba de una serie de procesos históricos entrelazados de desigualdad muerte que se han acumulado (Ojeda et al, 2015)

En la región, los cultivos de caña, tabaco, arroz, y recientemente de palma aceitera, y árboles maderables ha sido parte histórica de los espacios de explotación, exclusión y despojo (Ojeda, 110). La historia agrícola en los Montes de María inicia con las bonanzas en el tabaco, caña y arroz los cuales consolidan la agricultura, además de la ganadería, vocación que se encuentra representada en 268.026 has y la vocación para ganadería corresponde a 71.296 has; sin embargo, de acuerdo con el uso actual del suelo, hay un predominio de tierras en pastos con un total de 406.119 has (73\% en pastos no tecnificados), mientras que en agricultura se usan sólo 165.068 has" (ILSA, 2012: 41 ) 
Otra característica relevante, el desarrollo rural en Montes de María está basado en la Economía Campesina, caracterizada fundamentalmente por una producción agropecuaria familiar, con pequeñas unidades de tierra, uso intensivo de la mano de obra familiar, alto nivel de autoconsumo de la producción y diversificación de actividades generadoras de ingreso al interior del hogar.

Las alianzas productivas como modelo han generado "unas dinámicas de endeudamiento y financiarización del campo. Muchos han expresado haber perdido sus tierras, debido a las obligaciones financieras en las que incurren con la empresa tras la adquisición de semillas y agroquímicos" (Ojeda, 113: entrevista, febrero 2014).

¿Hay presencia de ecosistemas de especial importancia ecológica, ecosistemas estratégicos, áreas que hagan parte del Sistema de Parques Nacionales Naturales, humedales, páramos, zonas de manglar u otros?

¿Hay territorios étnicos?

\section{Impactos ambientales directos según las comunidades}

En primera instancia, los impactos del conflicto sobre las tierras, según datos del Registro único de predios y territorios abandonados, municipios como María la Baja, reconocida como despensa agrícola de la región y que producía gran cantidad de los alimentos que llegaban a Cartagena, se vio obligado a vivir el abandono de un gran porcentaje de sus tierras, por lo que en 2010, había 21.785 hectáreas abandonadas, de las 54.700 que cubre el municipio (Ramírez y Tobón)

El monocultivo, a partir del cual se encuentra la agricultura industrializada. Una agricultura que "acapara tierras, se contrapone a los modos y prácticas productivas de los agricultores a pequeña escala que tienden a los cultivos múltiples tradicionales. De acuerdo a D.L. Clawson (1985) (citado por Altieri, 2010) "muchas de estas plantas son variedades autóctonas (landraces), más heterogéneas genéticamente que las variedades modernas, y cuyas semillas han sido transmitidas de generación en generación. Estas variedades autóctonas son menos vulnerables, por lo que 
permiten aumentar la seguridad de las cosechas frente a enfermedades, plagas, sequías y otras inclemencias del medio" (p. 33).

Los bosques albergan una diversidad de fauna y son productores de agua; pero han sido afectados por la deforestación, que ocasiona problemas ambientales de deslizamientos, erosiones de suelos y deterioro del hábitat de la fauna. Además, las actividades agropecuarias de subsistencia que se realizan en laderas empinadas y nacimientos de cuencas hidrológicas causan daños ambientales a los recursos naturales. Para controlar estos factores negativos fueron creadas dos zonas de reservas naturales protectoras con el objeto de conservar, estudiar e investigar los recursos hídricos, la fauna y la flora (Aguilera, 2)

Mapa. Conflictos en el uso del suelo en los Montes de María.

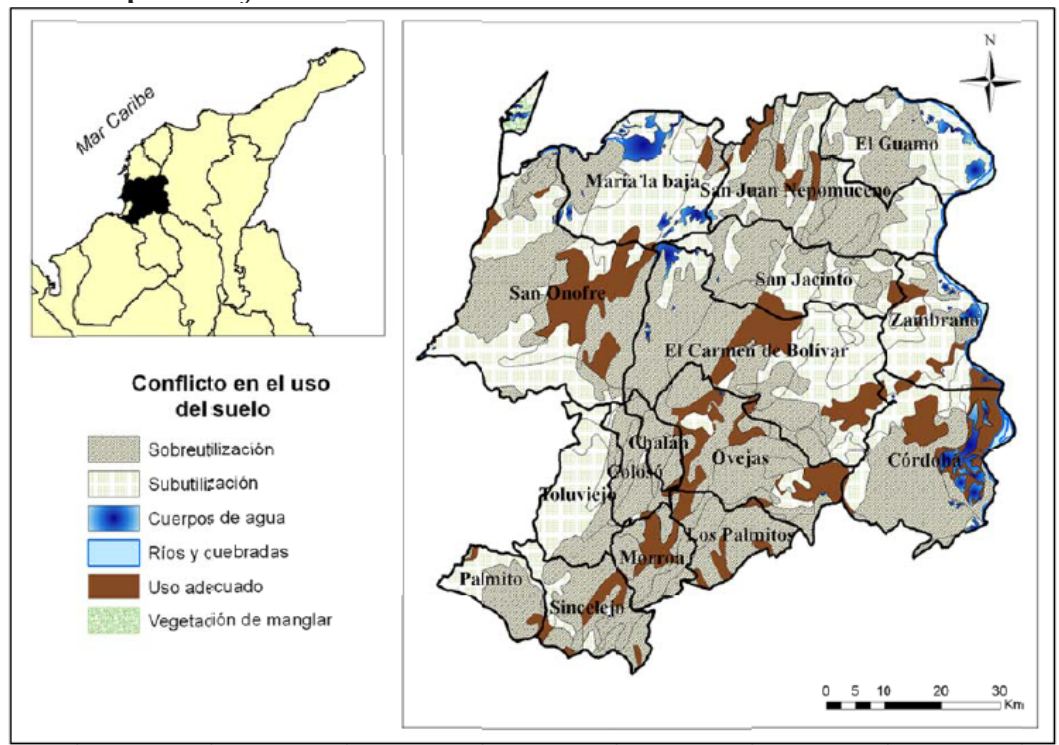

Fuente: Elaboración propia con datos del IGAC.

Mapa. Uso del suelo 


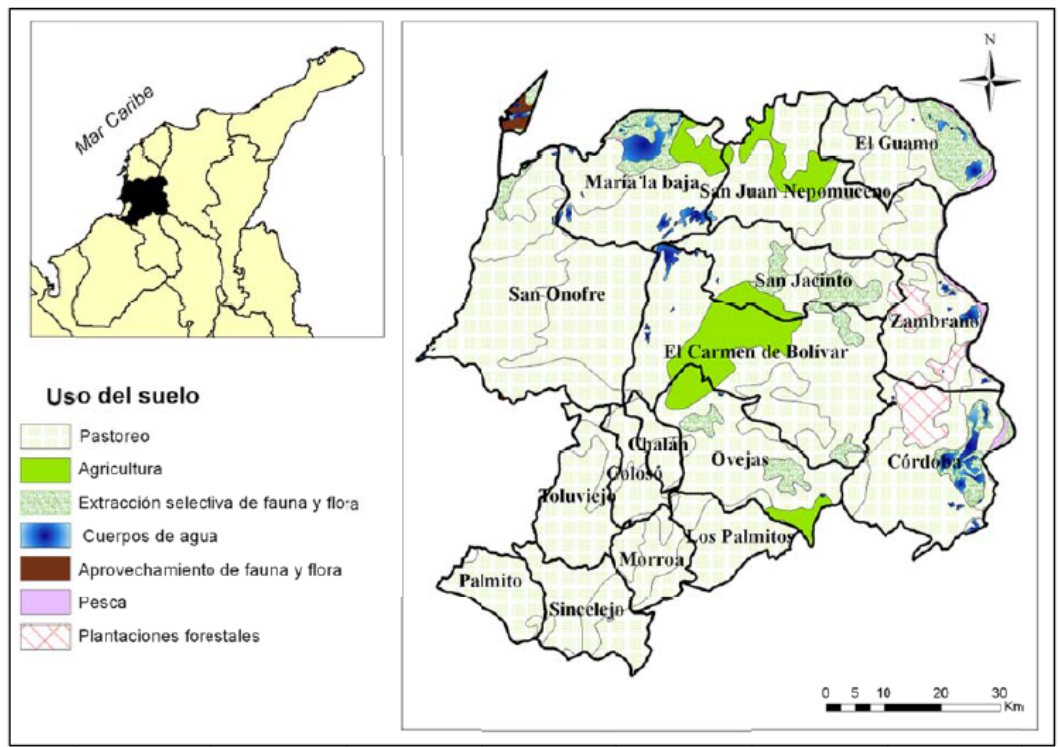

Fuente: Elaboración propia con datos del IGAC.

El mapa ilustra "los conflictos entre suelos aptos y su uso, observándose la sobreutilización la cual genere degradación de los recursos naturales y procesos erosivos; y la subutilización de las tierras se presenta cuando el uso actual de la tierra es inferior a la vocación de su uso principal, de acuerdo con la mayor capacidad productiva natural, restringiéndose el cumplimiento de la función social y productiva de las tierras" (Aguilera, 2013: 24).

La consecuente pérdida de biodiversidad expone a los campesinos más vulnerables a mayores riesgos ambientales, lo cual es corroborado en entrevistas ("El campo tiene sed, 2016") dada la aplicación de químicos como fertilizantes, insecticidas, herbicidas y plaguicida para la producción de la palma africana.

[José Luis Miranda]: "al utilizar os playones y terrones alrededor de terrenos de los cuerpos agua se está cambiando la vegetación natural porque se incluye la palma que no es una especie vegetal de la zona sino traída, lo cual cambia los ciclos naturales. Hay menos agua, y lo poco está contaminada, los arroyos se secan por deforestación. No cuentan con distrito de riego por la inundación, para la palma desperdician mucha agua". 


\section{5. ¿Cuál es la importancia del lugar o ecosistema donde se genera el conflicto?}

La diversidad biológica de la subregión Montes de María la conforman los bosques secos tropicales y de manglar, recursos hídricos, formaciones coralinas de playas marinas y una variedad de flora y fauna (Anexos 5 y 6). Los bosques son albergue de fauna silvestre y productores de agua, aunque han sido sometidos a un proceso de deforestación. Los recursos hídricos y ecosistemas asociados están conformados en este caso específico por aguas lénticas como ciénagas y lagunas de María La Baja, Córdoba y Zambrano (Promontes, 2003 en Aguilera, 20)

Esta riqueza hídrica, configura un territorio de un alto valor ambiental por los ecosistemas presentes, y por los ecosistemas compartidos como el Canal del Dique y el complejo de ciénagas aledañas y el Distrito de Riego de María la Baja, lo que requiere para su manejo la concertación con los entes territoriales y con CORMAGDALENA y CARDIQUE.

La subregión Montes de María tiene el 48,3\% de sus suelos con potencial agrícola y agroforestal y el $42,7 \%$ de su población es rural. Sus principales cultivos tradicionales son maíz, arroz, yuca, ñame, ajonjolí, plátano, tabaco, café, aguacate, maderables y frutales. Recientemente, se han incorporado nuevos cultivos comerciales como la palma africana, el ají picante y el cacao. Dentro de las actividades pecuarias, la ganadería vacuna es la de mayor importancia. También se destaca la apicultura (Aguilera, 24).

La forma cómo se utiliza la tierra así como los cuerpos de agua son trascendentales para el mantenimiento del ecosistema; debido a que éste es fuente de subsistencia para las dinámicas humanas y socio-económicas

\section{Aspectos sociales}

Las dos quintas partes de la población de la subregión de Montes de María viven en el campo, lo que corresponde a casi el doble del porcentaje de ruralidad del país. Aunque esta comunidad rural tiene acceso a amplios recursos naturales (bosques y tierras cultivables), presenta altos niveles de pobreza por las deficiencias en el acceso a los servicios básicos domiciliarios 
(electricidad, agua, alcantarillado), educación, salud y empleo (Aguilera, 2013: 3)

Las tomas campesinas de tierras son otra dinámica en la lucha por parte de los pobladores, lo cual generó una respuesta clara de los grandes terratenientes y las élites locales a través de la financiación de ejércitos privados o autodefensas, los cuales en la década de los noventa se conforman como paramilitares. La presencia paralela de guerrillas aumenta las acciones de los paramilitares contra la población civil de la zona rural ya criminalizadas, porque los campesinos se convierten en potenciales guerrilleros desde el discurso oficial y por consiguiente, en "enemigos paradigmáticos" de la paz y el desarrollo (Ojeda, 110).

De esa forma, se da la transición y se caracteriza el fenómeno de acaparamiento reciente en la región. En el año 2008 empiezan a llegar todos los empresarios, en carros blindados, generando temor entre los habitantes rurales. Se inician así, los encerramientos, cortan el acceso al agua, a los caminos, así los hacen y continúan haciendo" (ILSA, 2012. Líder campesino, Ovejas, junio de 2013).

El proceso de despojo se fundamenta en "el dominio territorial de los actores armados ilegales en los Montes de María, se alió con los intereses del capital en el reordenamiento territorial, consolidando así la concentración masiva de tierras y la implementación del nuevo modelo de desarrollo agroindustrial, el cual requiere de grandes extensiones de tierra para ser competitivo y rentable" (ILSA, 2012, 12). En ese sentido, el desplazamiento forzado de población civil ha estado predominantemente asociado al control territorial y a los crímenes cometidos por el paramilitarismo, al tráfico de drogas, y a la concentración de tierras para desarrollar grandes proyectos de agricultura comercial de maderables y agro combustibles" (PODEC, 2010: 77).

La situación se profundiza con la tensión entre las comunidades campesinas y las empresas, como lo expresa el líder Eliécer Rodríguez: "No tenemos agua ni tierras para cultivar" (El campo tiene Sed, 2016).

[Jesús Pérez Señas]: "aquí hay agua suficiente para todos, la comunidad padece, por el agotamiento de agua. Agrega, aquí nos damos cuenta que los monocultivos de palma tienen prioridad sobre los seres humanos, se suministra una cantidad de litros de agua a estos cultivos, no hay acceso 
al agua. Los campesinos y la comunidad han tomado la decisión de cerrar compuertas de represa en San José del Playón”. Eliécer Rodríguez, agrega: "Necesitamos sembrar, pero por medio de la palma nos estamos acabando. Conservar el embalse es determinante".

En esa medida se configura un punto de tensión en la relación, se refiere al acceso del agua con respecto al distrito de riego, el cual pasó a la asociación de Usuarios de María La Baja (Usomaría), cuyo cambio en la figura de la propiedad y administración del distrito de riego relegó a muchos pobladores locales que no contaban con títulos de propiedad ni los recursos necesarios para ser miembros de la asociación. De igual forma, las parcelas productivas bajo figuras comunitarias, no fueron tenidas en cuenta por las políticas estatales dada su carencia de título de propiedad individual (Ojeda et al. 2012: 114).

De esta manera, encontramos una serie de actores que juegan un papel clave en estas dinámicas. Desde una posición más hegemónica, la empresa Oleoflores bajo la directriz de Murgas. Por otra parte, desde la base de la acción de los colectivos en este caso en María La Baja y Ovejas, se agrupan la Asociación de campesinos retornados de Ovejas, Asociación de Campesinos de San José del Playón y Organizaciones de Población Desplazada (OPD) de María La Baja.

\section{Causas: dinámica y patrón del conflicto}

El posicionamiento de la agroindustria en el territorio de María la Baja y Ovejas en una transición hacia el postconflicto, se lleva a cabo mediante proyectos de desarrollo rural con cultivos extensos de palma africana y teca. Sin embargo, a través de las nacientes alianzas productivas implica los procesos de privatización de la tierra y el papel que han desempeñado la empresarización y la proletarización de pobladores rurales en el municipio de María la Baja" (Ojeda, 112)

El caso de los Montes de María tiene como patrón los cambios en la tenencia y el uso de la tierra, primero por el despojo de tierras cuando el conflicto se encontraba en un punto álgido y agua en Colombia, profundizándose en años recientes y alcanzando un punto álgido de conflictividad y violencia con "200.000 casos de desplazamiento forzado, 
generó el despojo de más de 80.000 hectáreas de tierra entre 1997 y 2007" (De los Ríos, Becerra y Oyaga 2012, 32; Verdad Abierta 2012). Eso, teniendo en cuenta que el área cultivable calculada de la región para 2010 fue de 94.580 hectáreas (Incoder, 2010).

En ese contexto, los monocultivos de la palma de aceite para la producción de biocombustible, y de maderables como la teca y el eucalipto han ido creciendo entre compra masiva de tierras, alianzas con campesinos, el abandono de las parcelas y el despojo evidente.

La palma de aceite se comenzó a desarrollar en María La Baja en 1998, cuando los agricultores del distrito de riego entraron en crisis y abandonaron, arrendaron o subutilizaron sus tierras y se deterioró la infraestructura de riego. Entonces, decidieron integrar su economía campesina con una empresa agroindustrial. Para esto, los agricultores crearon la Asociación de Palmicultores del Distrito de Riego de María La Baja, Asopalma, con un esquema de alianza estratégica productiva y se integraron con la Promotora Hacienda Las Flores S.A., grupo empresarial que les aportó su experiencia en la agroindustria de la palma de aceite, tecnología y asistencia técnica en la producción, plantas de viveros y garantía en la compra del fruto. El costo del proyecto fue de 14.000 millones de pesos, de los cuales 700 millones fueron recursos no reembolsables del Fondo de Desarrollo Rural (DRI), el $40 \%$ del costo de las obras por Incentivo de Capitalización Rural (ICR) y el resto financiación del Fondo de Financiamiento Agropecuario (Finagro), a través de la Corporación financiera Cofinorte (Aguilera, 2002 de Aguilera, 2013: 20).

Entre 2001 y 2012, el área sembrada en palma de aceite en la subregión Montes de María creció en 21,6\% promedio anual, pasando de 900 a 9.702 hectáreas. Estos cultivos se iniciaron en María La Baja (Bolívar), municipio que se ha mantenido con la mayor área sembrada participando con el 85,7\% del total del cultivo en la subregión. Sin embargo, vale la pena destacar que en los dos últimos años se iniciaron siembras en San Onofre y Toluviejo (Sucre) y en Zambrano (Bolívar) (Aguilera, 2013: 46) 


\section{Contexto histórico que caracterice la interacción entre los diversos actores}

En la región, los cultivos de caña, tabaco, arroz, y recientemente de palma aceitera, y árboles maderables han sido parte histórica de los espacios de explotación, exclusión y despojo (Ojeda et al, 2015: 110). La historia agrícola en los Montes de María inicia con las bonanzas en el tabaco, caña y arroz los cuales consolidan la agricultura, además de la ganadería, vocación que se encuentra representada en 268.026 has y la vocación para ganadería corresponde a 71.296 has; sin embargo, de acuerdo con el uso actual del suelo, hay un predominio de tierras en pastos con un total de 406.119 has ( $73 \%$ en pastos no tecnificados), mientras que en agricultura se usan sólo 165.068 has" (ILSA, 2012:41)

En el año 2009 inicia a acabar el con conflicto, inician compras masivas de tierras y así la privatización de las vías, jagüeyes, y comienzan a privatizar las mismas parcelas donde el campesino hacía sus labores donde cultivaba, al comprar esas parcelas también son privatizadas sin tener la libertad que tenían antes en el territorio"... Después de privatizar (Entrevista Carmelo Márquez, documental, 2016). Por su parte, Víctor Manuel Aguas, agrega que los "Caminos y reservorios de agua eran públicos, para la comunidad La Finca fue repartida entre 19 familias, y estas hacen una dotación para las escuelas, los jagüeyes son públicos" (El campo tiene sed. 2016).

Actualmente, los distritos de riego privatizados, conduce a cambios relevantes en el acceso al agua. Murgas y su expansión de cultivos de palma han generado un impacto en la vida de los pobladores de las zonas aledañas a las represas y canales de riego. En la actualidad, gran parte de las 8500 hectáreas beneficiadas están cultivadas con palma aceitera (ILSA. Entrevista Alfonso Torres, María La Baja, Julio 2014). "Los cuerpos de agua del distrito de riego son la fuente de comida, la base de proyectos comunitarios, y uno de los motivos de luchas de distintas poblaciones que dependen de sus canales para vivir; sin embargo, el acceso al agua potable está restringida y no son aptas para el consumo humano ya que se encuentran contaminadas por fertilizantes y pesticidas que se vierten en las plantaciones de la palma" (Ojeda, 115). "el agua es de Murgas; los carreteables del canal y las bombas y las compuertas, son de él" (Jorge, María La Baja, febrero de 2014). 


\section{Las acciones de los actores frente al conflicto ambiental}

Los procesos y acciones que llevan a cabo las comunidades sobre la expansión de cultivos en el marco de la compra de tierras y entra palma de aceite y presenta una petición a cardique, minambiente, instituciones ambientales, que es siembra indiscriminada de la palma, en las zonas protectora de la represa, que está entre límite de zonas de protección y zona agrícola de la represa Geovaldys Gozález]:

Las organizaciones sociales de la zona no han logrado que Incoder determine el área de protección ambiental de la represa que está haciendo afectada por los cultivos de palma.

Los campesinos, los consejos comunitarios y los resguardos indígenas proponen como punto central la redefinición del modelo de desarrollo rural imperante en Colombia, y a cambio proponen un modelo de desarrollo rural incluyente y democrático. La iniciativa se centra así en las zonas de reserva campesina (ZRC), así como la conformación de una mesa de concertación, iniciativa está de las organizaciones sociales, con el fin de encontrar soluciones a las principales problemáticas que afrontan los campesinos, afrodescendientes e indígenas que la habitan (Ramírez $\&$ Tobón, 2012).

\section{Problemas centrales alrededor del conflicto}

Los impactos son claramente negativos, los pobladores de la zona se encuentran rodeados de palma y sin trabajo ni casa, demandando el acceso a las tierras perdidas con las alianzas productivas (Ojeda, 114). Observamos así la expansión de la "frontera", aquellas áreas de tierra en el proceso de ser convertidas en cultivos de palma africana, etc. Así, los paradigmas del desarrollo global y las narrativas políticas influencian como las áreas fronterizas son definidas y conocidas, y estos retos que los planeadores declaran, enfrentan al implementar los esquemas de los cultivos de palma africana (McCarthy \& Cramb, 2009).

En esa medida, en el modelo de desarrollo rural a nivel nacional se insta a los campesinos a ser rentables. En el foro de Desarrollo rural y Economía campesina 2011 en María la Baja: [Ustedes] No pueden seguir 
cultivando solamente lo que se comen... tienen que cultivar algo que puedan vender, que deje excedentes. Hacer todo lo que no pueden hacer cultivando simplemente la yuca, el maíz, lo que se come (Ojeda, 111 de OTEC, 2013).

Tal visión del desarrollo agrícola justifica un nuevo modelo que conduce a la expansión de cultivos de palma a través de la figura de las alianzas productivas, diseñada por el entonces exministro Carlos Murgas. En esa forma, encontramos en otras dinámicas resultantes del proceso de privatización de las tierras chocan los arreglos tradicionales de préstamo de mano de obra y uso colectivo de la tierra y es fundamentalmente problemático dado los bajos niveles de propiedad de las tierras. El monocultivo es descrito así: "la palma no quiere yuca, ni plátano, ni maíz cerca, quiere estar sola [...] la tierra queda destruida, [después] no se cultiva nada más allá" (Ramiro, María la Baja, Junio 2013).

En consecuencia, el modelo que generaba rentabilidad y que generaba empleo no logra su objetivo. "El cultivo de palma no genera tanto empleo. En diez hectáreas necesitas un solo palmicultor" (Ever, María la Baja, junio de 2013). "Quienes acceden a los pocos trabajos disponibles, se convierten en obreros agroindustriales en labores de siembra, fumigación y recolección, trabajo que se caracteriza por las condiciones precarias ya que no quiere mano de obra todo el año y los salarios están por debajo del mínimo legal y la contratación a través de cooperativas les permite saltarse a las empresas la legislación laboral" (Ojeda, 113, de Salinas Abdala 2012, 189-190).

Oleoflores se presenta como el aceite que "resucitó" a María la Baja (Ojeda 113 de Salinas Ortegón, 2012) por ende, como un proyecto productivo, rentable y sostenible cuyos logros muestran en generar fuentes de empleo lícito a los agricultores y sus familias y proteger a los pequeños productores de la pérdida de sus parcelas por presión de la violencia (Oleoflores, 2014).

Por otra parte, y en ese sentido, las carreteras construidas para el transporte de insumos y los productos son presentadas como formas de responsabilidad social empresarial, y las amplias extensiones verdes de palma y teca pasan por proyectos de sostenibilidad ambiental en el reporte de Argos 2014. 
Dada las condiciones socioeconómicas de los habitantes más afectados, el principal impacto se centra en el deterioro de las condiciones de subsistencia y en la economía familiar. En ese sentido, se observa que tomando en cuenta que la soberanía alimentaria "enfatiza el acceso de los agricultores a la tierra, las semillas y el agua, se enfoca en la autonomía local, los mercados y ciclos de consumo y de producción locales, la soberanía energética y tecnológica, y las redes de campesino a campesina" (Altieri, 2010 , p. 29). Las condiciones establecidas a causa del desplazamiento y al despojo de pobladores locales en el territorio, dan paso a la concentración y el cercamiento de las tierras.

\section{Dos visiones sobre el desarrollo territorial en los Montes de María}

El conflicto aún persiste, sin embargo los motivos que movilizan a los campesinos, afrodescendientes e indígenas son la defensa y protección de su territorios y de su cultura, el derecho a la vida, una economía campesina próspera y que les permita vivir en buenas condiciones, su permanencia tranquila en el territorio, así como la garantía de un desarrollo territorial agrario y rural, y cuya productividad, respete, proteja y promueva los usos sociales, ambientales, culturales, tecnológicos y políticos del mismo (Ramírez \&Tobón, 2012).

De otro lado, los gobiernos de países en desarrollo adoptan la visión del desarrollo agrícola como como expuso Adesina, ministra de agricultura de Nigeria: miramos la agricultura como actividad de desarrollo, como un sector social en el cual gerencias a los pobres de las zonas rurales. Pero, la agricultura no es un sector social. La agricultura es un negocio.

La semilla es un negocio, los fertilizantes son negocios, el almacenamiento, el valor agregado, la logística y el transporte, todo se trata de negocios (Hobbes, 2016). Tal visión sienta las condiciones políticas y jurídicas que los gobiernos brindan para atraer y proveer seguridad a las inversiones agrícolas extranjeras tan favorables que garantizan la seguridad alimentaria de otros países a costa de la población local. 


\section{Conclusiones}

La validez empírica de la crisis ambiental y social por la que atraviesa la subregión de los Montes de María exige justicia ambiental y social. Desde el tema que nos ocupa, el acaparamiento de tierras es considerado una fuente de problemas y bajo el cual se coloca en evidencia visiones encontradas sobre el desarrollo territorial. A lo largo de estas líneas se ha señalado como éste elemento es transado de acuerdo a los intereses de cada actor.

Por un lado, están quienes la trabajan a escala local y encuentran en ella no solo una forma de satisfacer sus propias necesidades básicas sino las de otros por medio del alimento; por el otro lado, a una escala más amplia está el Estado, quien ve en la tierra un elemento consecuente hacia un mayor desarrollo económico y social del territorio. Sin embargo, parte de la naturaleza del Estado es esa, el problema radica en la forma cómo lo hace y cuál es la población que realmente se beneficia.

El último actor es la empresa transnacional, cuyas políticas que los benefician emanan de instituciones globales como la OMC, y que concibe a la tierra más como un bien de explotación. Estas visiones encontradas fueron creciendo a medida que se iba dando la transición de la agricultura familiar y campesina a la industrial, tomando como argumento central la necesidad de garantizar la seguridad alimentaria universal a través del eje tecnológico e industrial. Resultado de ello, es en la economía local campesina.

Hoy en día, y en aras de superar el fenómeno del acaparamiento tierras, han surgido una serie de visiones con respecto a la posible solución de la problemática entre los actores sociales y políticos, uno como amenaza y otros como oportunidad. Eso implica replantear desde una contextualización profunda, el modelo de desarrollo rural ante la desregulación de las inversiones y el modelo de desarrollo de las empresas.

Por lo tanto, un primer paso será entonces, reconceptualizar del desarrollo rural tomando elementos clave de la soberanía alimentaria, y que inste al reconocimiento de nuevos actores en la gobernanza.

Colombia requiere especial análisis por entrar en una etapa de posconflicto bajo el marco de la implementación de los Acuerdos de la Habana, para ello la figura de las Zonas de Reserva Campesina, es necesario implementarlas para contrarrestar los niveles de conflictividad social 
y política que dieron en su momento origen al conflicto armado, y que se fueron profundizando a lo largo de éste. Por lo tanto, surge aquí un elemento crítico, bajo dos componentes, formalización de la propiedad y flexibilización de la UAF, en relación a la construcción de capacidades en los territorios en postconflicto.

Basado en lo anterior, es pertinente profundizar en la investigación que identifique de forma más aguda los patrones y factores determinantes desde el punto de vista sistémico conducentes a los conflictos a medida que la frontera agrícola se expanda y cuando los eventos climáticos irregulares se profundicen.

\section{Referencias}

Aguilera Díaz, María (2013). Montes de María: Una subregión de economía campesina y empresarial. Documentos de Trabajo de Economía Regional. $\mathrm{N}^{\circ}$ 13. Noviembre.

Alier, J. M. (2001). Justicia ambiental, sustentabilidad y valoración. Ecología política, (21), 103-134.

Altieri, M. A. (2010). I. ¿Por qué la agricultura campesina? Agroecología, movimientos sociales y políticos a favor de la soberanía alimentaria. En J. Gascón, \& X. Montagut, ¿Cambio de rumbo en las políticas agrarias latinoamericanas? (p.p. 27-42). Barcelona: Icaria.

Andersen, A. O., Bruun, T. B., Egay, K., Fenger, M., Klee, S., Pedersen, A. F., Pedersen, L. M. L. and Suárez Villanueva, V. (2016), Negotiating development narratives within large-scale oil palm projects on village lands in Sarawak, Malaysia. Geogr J, 182: 364-374. doi:10.1111/ geoj. 12181

Bernstein, H. (2015). Food Regimes and Food Regime Analysis: A Selective Survey.

Borrás Jr., S. M., Franco, J. C., \& Wang, C. (2013). The challenge of global governance of land grabbing: changing international agricultural context and competing political views and strategies. Globalizations, 10(1), 161-179.

Gudynas, E. (2008). Un análisis preliminar de las transformaciones recientes en la agricultura Latinoamericana. Economía Crítica y Desarrollo, 167-191. 
Hobbes, Michael (2016). The Untouchables: Why it's getting harder to stop multinational corporations. Foreign Policy. April 11. Recuperado de http://foreignpolicy.com/2016/04/11/the-untouchables-zimbabwe-green-fuel-multinational-corporations/

ILSA. (2012). Montes de María. Entre la consolidación del territorio y el acaparamiento de tierras. Aproximación a la Situación de Derechos Humanos y del Derecho Internacional Humanitario en la región (2006-2012). Recuperado el 18 de Octubre de 2013, de http://ilsa. org.co:81/biblioteca/dwnlds/otras/montesl/informe.pdf

Informe del Banco Mundial Colombia, 2006-2010

Luna Galván, M. (2012). Biofuels Expansion and Their Differentiated Social-political Impacts in Developing Countries: A Comparative Account between Land Grabs and Social Sustainability in Honduras. Lund: Lund University Publications.

Margulis, M. E., \& Porter, T. (2013). Governing the global land grab: multipolarity, ideas, and complexity in transnational governance. Globalizations, 10(1), 65-86.

McMichael, P. (2005). Global development and the corporate food regime. New Directions in the Sociology of Global Development Research in Rural Sociology and Development, Volume 11, 269-303

Nally, D. (2015). Governing precarious lives: land grabs, geopolitics, and 'food security'. The Geographical Journal, 181: 340-349. doi:10.1111/geoj. 12063

Nardi, A. (2011). Thesis: Rural Development and Territorial Dynamics in the Province of Misiones, Argentina. Lund: Lund University. http:// lup.lub.lu.se/record/1852579

Ojeda, D., Petzl, J., Quiroga, C., Rodríguez, A. C., \& Rojas, J. G. (2015). Paisajes del despojo cotidiano: acaparamiento de tierra y agua en Montes de María, Colombia. Revista de Estudios Sociales, (54), 107-119.

Phuhlisani Solutions (2009). International and local approaches to rural development. Key issues and questions: A review of the literature for the Drakenstein Municipality. 
Del despojo al acaparamiento de tierras: los conflictos socio-ambientales emergentes en los Montes de María alrededor de la expansión de la palma africana y la teca

Plan Municipal de Gestión del Riesgo de Desastres Del Municipio de María La Baja. Consejo Municipal para la Gestión del Riesgo de Desastres CMGRD. Junio del 2013.

Ramírez, Nyria \& Tobón, Gabriel (s.f) Observatorio de Territorios Étnicos. UNCTAD. (2015). El papel de los pequeños agricultores en la producción y el comercio sostenibles de los productos básicos Informe de la secretaría de la UNCTAD. GE.15-12875.

Vargas Ramírez, Nicolás (2012). Modelos de desarrollo en Montes de María: ¿posible coexistencia? AECID y Pontificia Universidad. Diciembre. 